\title{
Critical appraisal of the differential effects of antihypertensive agents on arterial stiffness
}

\author{
This article was published in the following Dove Press journal: \\ Integrated Blood Pressure Control \\ 3 June 2010 \\ Number of times this article has been viewed
}

\author{
Francesca Kum \\ Janaka Karalliedde \\ Unit for Metabolic Medicine, \\ Cardiovascular Division, \\ Kings College-Waterloo Campus, \\ King's College London, United \\ Kingdom
}

Correspondence: Janaka Karalliedde Unit for Metabolic Medicine, Cardiovascular Division, 3rd Floor, Franklin-Wilkins Building, King's College London, London SEI 9NH, United Kingdom

Tel +44 (0) 2078484464

$\mathrm{Fax}+44$ (0) 2078484567

Email j.karalliedde@kcl.ac.uk

\begin{abstract}
Increased central arterial stiffness, involving accelerated vascular ageing of the aorta, is a powerful and independent risk factor for early mortality and provides prognostic information above and beyond traditional risk factors for cardiovascular disease (CVD). Central arterial stiffness is an important determinant of pulse pressure; therefore, any pathological increase may result in left ventricular hypertrophy and impaired coronary perfusion. Central artery stiffness can be assessed noninvasively by measurement of aortic pulse wave velocity, which is the gold standard for measurement of arterial stiffness. Earlier, it was believed that changes in arterial stiffness, which are primarily influenced by long-term pressure-dependent structural changes, may be slowed but not reversed by pharmacotherapy. Recent studies with drugs that inhibit the renin-angiotensin-aldosterone system, advanced glycation end products crosslink breakers, and endothelin antagonists suggest that blood pressure (BP)-independent reduction and reversal of arterial stiffness are feasible. We review the recent literature on the differential effect of antihypertensive agents either as monotherapy or combination therapy on arterial stiffness. Arterial stiffness is an emerging therapeutic target for CVD risk reduction; however, further clinical trials are required to confirm whether BP-independent changes in arterial stiffness directly translate to a reduction in CVD events.
\end{abstract}

Keywords: aortic pulse wave velocity, augmentation index, blood pressure, renin-angiotensinaldosterone system

\section{Introduction}

Hypertension is an increasingly prevalent condition, managed with a combination of lifestyle changes and increasingly by various pharmacological agents. These agents include the $\beta$-blockers, diuretics, calcium channel blockers (CCB), and drugs that interfere with the renin-angiotensin-aldosterone system (RAAS) pathway such as angiotensin-converting enzyme inhibitors (ACE-I), angiotensin receptor blockers (ARB), and aldosterone antagonists.

Currently, blood pressure (BP) is routinely measured in the clinical setting by brachial sphygmomanometry. However, prior to the routine use of the sphygmomanometer, the importance of arterial aging and the characteristics of the arterial pressure pulse wave as a bedside index of arterial aging were well documented. ${ }^{1}$ Abnormalities in the pulse wave shape were in fact used more than 100 years ago to diagnose hypertension and to demonstrate effects of drugs such as nitrates. ${ }^{1}$ Systolic pressure waves are augmented during transmission to the periphery; therefore, emerging evidence suggests that peripheral BP is only an indirect correlate of central aortic pressures. Importantly, the magnitude of such augmentation is dependent on stiffness of conduit vasculature, 
described as central arterial stiffness. Central hemodynamic parameters, such as central systolic BP, pulse pressure (PP), and the augmentation index (AIx), are important determinants of cardiac workload. These can be measured noninvasively at the radial artery using sensitive methods. ${ }^{1,2-6} \mathrm{AIx}$ is calculated as the ratio of the augmentation pressure (AP), the amplification of peak systolic BP, which is in turn due to the reflected systolic wave, to the PP $(\mathrm{AIx}=\mathrm{AP} / \mathrm{PP})$, Figure $1 .^{2}$

Aortic pulse wave velocity (Ao-PWV) is recognized as the current gold-standard measure of arterial stiffness. ${ }^{2}$ Ao-PWV can be determined from carotid and femoral pressure waveforms obtained noninvasively by applanation tonometry. Pressure waveforms are referenced to a concurrently recorded electrocardiography (ECG), and carotid to femoral transit time $(\Delta T)$ is calculated from the foot-to-foot time difference between carotid and femoral waveforms. The distance between the surface markings of the sternal notch and the femoral artery is used to estimate the path length between the carotid and femoral arteries $(L)$ and Ao-PWV is computed as $L / \Delta T$. This technique is a reproducible and noninvasive method validated in a range of clinical settings and trials. ${ }^{2}$

Arterial stiffness, as evaluated by Ao-PWV, has been extensively studied in recent years and is an established

A

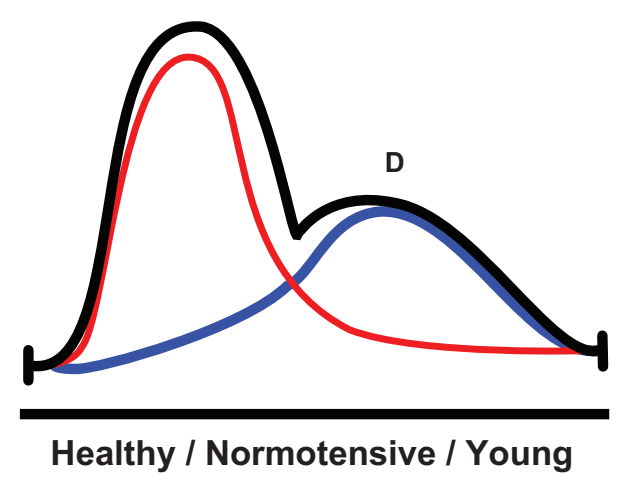

independent predictor of cardiovascular risk; both fatal and nonfatal cardiovascular events and all cause mortality in hypertensive patients, in addition to an independent predictor of coronary heart disease and stroke in the healthy population. ${ }^{2,5}$

It is important to note the differences between AIx and Ao-PWV both of which are markers of arterial stiffness. AIx is known to be influenced by gender, heart rate, and body habitus in addition to BP and age. ${ }^{7,8} \mathrm{~A}$ transfer function derived from invasive studies is used to estimate central aortic pressure, APs, and AIx. Often there is poor correlation between Ao-PWV and AIx and some drugs can influence 1 parameter independently of the other. In fact, AIx and Ao-PWV may not reflect the same arterial wall properties with AIx being a surrogate index for the stiffness of resistance vessels (arterioles), whereas Ao-PWV is an indicator of aortic stiffness. Indeed, AIx and Ao-PWV can change independently of each other due to the elastic properties of the aorta and the adaptive responses of the endothelium. ${ }^{7-9}$

Furthermore, the age-related changes in AIx and Ao-PWV are nonlinear. Some suggest that AIx is a more sensitive marker of central arterial stiffness in younger adults as compared with Ao-PWV, an index that changes

B

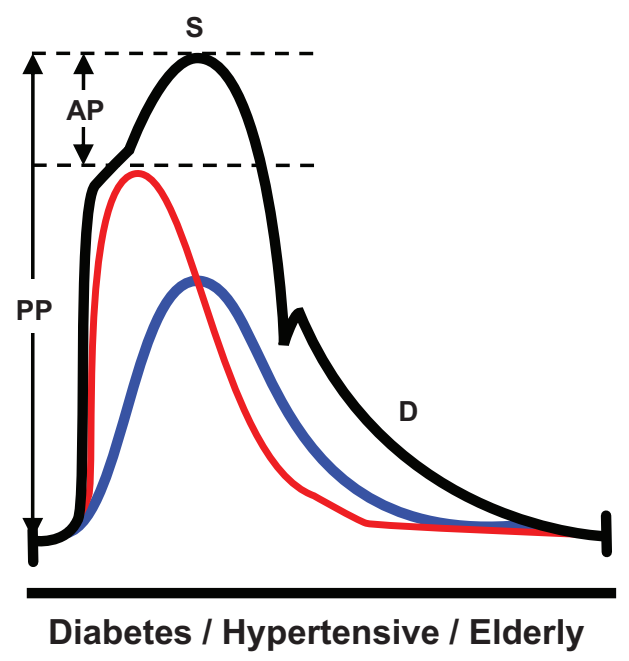

Forward systolic wave

Reflected wave, from peripheral arterial branch points.

Combined pulse wave.

Figure I Schematic of arterial pressure waveforms and calculation of augmentation index (Alx) ${ }^{3,4}$ A) Pulse waveforms in healthy compliant vasculature, timing of rebound wave reflection occurs during diastole (D). B) Pulse wave reflection is faster and earlier in stiffer arteries, thus amplifying the measured systolic BP peak (S), and reducing diastolic pressures (D), hence pulse pressure (PP) is increased (total height of combined pulse wave peak).

Abbreviation: AP, augmentation pressure. 
more prominently in older patients, in whom it is reported to better reflect arterial stiffness. ${ }^{10,11}$

Generally, Ao-PWV is accepted as the superior marker of arterial stiffness and many clinical studies have demonstrated the impact of aortic stiffness on cardiovascular disease (CVD) mortality and morbidity. ${ }^{2}$ A longitudinal study by Laurent et al ${ }^{12}$ demonstrated that aortic stiffness is a predictor of fatal stroke in patients with essential hypertension. In patients with chronic kidney disease, Blacher et al ${ }^{13}$ reported that an increase of $1 \mathrm{~m} / \mathrm{s}$ Ao-PWV is associated with $34 \%$ (and $14 \%$ after adjustments for other CVD risk factors) increase in cardiovascular and overall mortality. The reversibility of arterial stiffness in this patient group is a key modifiable risk factor for survival. ${ }^{14}$ Further epidemiological studies associate a raised arterial stiffness and central BP parameters with other underlying pathologies, such as left ventricular hypertrophy, carotid intima-media thickness, and endothelial dysfunction. ${ }^{3,15,16}$

A typical Ao-PWV in a healthy 25 -year-old is $5 \mathrm{~m} / \mathrm{s}$, which then increases with age to around $8-9 \mathrm{~m} / \mathrm{s}$ at $60-75$ years. $^{2}$ Values above $13 \mathrm{~m} / \mathrm{s}$ are a strong independent predictor of cardiovascular mortality. ${ }^{17}$ Arterial stiffness increases with normal ageing; however, as aforementioned, this ageing process is accelerated by coexisting hypertension, diabetes, metabolic syndrome, hypercholesterolemia, and arteriolosclerosis. . $, 4,16,18^{2}$ For example, patients with type 2 diabetes mellitus (T2DM) have a $1 \mathrm{~m} / \mathrm{s}$ faster Ao-PWV than BP-matched nondiabetic subjects. ${ }^{2,16}$ Ethnic and gender variations in arterial stiffness have also been described. ${ }^{2}$ At present, normograms that describe the normal Ao-PWV for different ages are not available. However, such reference ranges specific for age and gender may be available for use in the near future.

The primary underlying pathology of increased arterial stiffness is attributable to the fragmentation and degradation of normal elastin, which is consequently replaced by stiffer abnormal collagen during the ageing process. Advanced glycation end products (AGEs) are abundance in the hyperglycemic and chronic diabetic patients., ${ }^{2,416,18}$ Nonenzymatic AGE crosslinkage affects both elastin and collagen, but preferentially collagen, which is also more stable and has a slower turnover rate. AGE interaction with the specific receptors for AGE further contributes to vascular damage and endothelial dysfunction resulting from the inflammatory responses that are triggered, namely the increased expression of reactive oxygen species, proinflammatory cytokines, nuclear factor kappa B cells (NF-kB), growth factors, endothelin, vascular adhesion molecules, and the recruitment of monocytes. ${ }^{4,17,18}$
Oxidative and mechanical stresses mediate vascular remodeling of the extracellular matrix, via the enzymatic actions of the catabolic matrix metalloproteases. Inflammatory cell and cytokine recruitment may contribute to the dysregulation of this enzyme family, thus resulting in pathological alterations of vascular wall composition and morphology, and an increased arterial stiffness. ${ }^{4,18}$ Furthermore, angiotensin II has been shown, both in vitro and in animal studies, to mediate a number of effects from increased collagen synthesis to proliferation of smooth muscle cells, arterial wall fibrosis, accumulation and activation of inflammatory cells. ${ }^{19}$

There is significant variability in the effects of antihypertensive drugs on arterial stiffness. This variability is due to the duration of treatment, the measure of arterial stiffness employed, and the magnitude of blood reduction observed. Importantly, as arteries are stiffer at higher BPs, due to the curvilinear relationship between arterial pressure and volume, arterial stiffness may decrease with any intervention that lowers BP. ${ }^{1}$ It is, therefore, often difficult to formally distinguish between the passive reductions in arterial stiffness due to reduction in BP from the pressure-independent alterations of the arterial wall. Drugs, such as ACE-I, ARB, and aldosterone antagonists, seem to improve large artery compliance independently of BP changes, probably acutely by inducing functional changes such as vascular smooth muscular relaxation and in the long term by decreased arterial wall thickness, collagen content, and reversal of smooth muscle cell hypertrophy. ${ }^{2,6,7,16,18,19}$

Research addressing the mechanism of action, direct class effects, and efficacies of antihypertensive therapies on BP has been extensively reviewed and national and international guidance and consensus statements are available ${ }^{20,21}$ hence, this review focuses on the recent literature that compares and contrasts head-to-head trials of antihypertensive therapy on arterial stiffness as assessed primarily by Ao-PWV and the AIx.

Tables 1 and 2 summarize the main effects of the major classes of antihypertensive agents on Ao-PWV and AIx when used as monotherapy and in combination therapy.

\section{Conduit Artery Function Evaluation (CAFE) study: combination of $\beta$-blocker and bendroflumethiazide vs CCB and ACE-I}

This landmark randomized, controlled clinical trial was a vascular-orientated substudy of the Anglo-Scandinavian Cardiac Outcomes Trial. ${ }^{6}$ Patients had either untreated 
Table I Effects of different antihypertensive agents on arterial stiffness

\begin{tabular}{|c|c|c|}
\hline Class & $\begin{array}{l}\text { Effect on } \\
\text { Ao-PWV }\end{array}$ & $\begin{array}{l}\text { Effect on central aortic } \\
\text { pressures and Alx }\end{array}$ \\
\hline Thiazide diuretics ${ }^{24}$ & Neutral & Neutral \\
\hline \multicolumn{3}{|l|}{$\alpha$-blockers } \\
\hline Doxazosin ${ }^{37,38}$ & Neutral & Neutral \\
\hline \multicolumn{3}{|l|}{$\beta$-blockers } \\
\hline Atenolol ${ }^{25,28,29}$ & Reduce & Increase \\
\hline Nebivolol, ${ }^{35}$ vasodilating & Reduce & Reduce \\
\hline \multicolumn{3}{|l|}{$\beta$-blocker } \\
\hline $\mathrm{CCB}^{23,28,32}$ & Reduce & Reduce \\
\hline \multicolumn{3}{|l|}{ RAAS blockers } \\
\hline Aldosterone antagonists ${ }^{32}$ & Reduce & Reduce \\
\hline$A C E-I^{28,33}$ & Reduce & Reduce \\
\hline $\mathrm{ARB}^{23,29,33}$ & Reduce & Reduce \\
\hline
\end{tabular}

Abbreviations: ACE-I, ACE inhibitor; ARB, angiotensin receptor blocker; Alx, augmentation index; Ao-PWV, aortic pulse wave velocity; $C C B$, calcium channel blocker; RAAS, renin-angiotensin-aldosterone system.

hypertension or treated hypertension, and to be eligible, patients had to have at least 3 additional cardiovascular risk factors from the following: male sex, smoker, age $>55$ years, left ventricular hypertrophy, ECG abnormalities consistent with evidence of ischemic changes, T2DM, peripheral arterial disease, cerebrovascular disease, microalbuminuria or proteinuria, a ratio of total plasma cholesterol to high-density lipoprotein cholesterol of $\geq 6$, or a family history of premature coronary heart disease. Eligible patients were randomized to 2 treatment regimes, the aims being to compare the effects of traditional combination antihypertensive therapy of atenolol \pm thiazide with a more contemporary combination therapy of the dihydropyridine CCB amlodipine \pm ACE-I perindopril. The objectives of the CAFE study were to prospectively study the effects of these combinations on the relationship between central and peripheral arterial BP; arterial stiffness as indicated by the extent of arterial pressure wave

Table 2 Effects of combination therapy of different classes of antihypertensive agents on arterial stiffness

\begin{tabular}{|c|c|c|}
\hline Combination & $\begin{array}{l}\text { Effect on } \\
\text { Ao-PWV }\end{array}$ & $\begin{array}{l}\text { Effect on central } \\
\text { aortic pressures } \\
\text { and Alx }\end{array}$ \\
\hline $\mathrm{ACE}-\mathrm{I}+\mathrm{CCB}^{6}$ & Neutral & Reduce \\
\hline $\begin{array}{l}\text { Thiazide + potassium-sparing } \\
\text { (amiloride) diuretic }{ }^{26,27}\end{array}$ & Neutral & Reduce \\
\hline ACE-I + indapamide ${ }^{25}$ & Reduce & Reduce \\
\hline $\mathrm{ARB}+\mathrm{CCB}^{24}$ & Reduce & Reduce \\
\hline $\mathrm{ARB}+$ thiazide diuretic ${ }^{23}$ & Reduce & Reduce \\
\hline
\end{tabular}

Abbreviations: ACE-I, ACE inhibitor; ARB, angiotensin receptor blocker; Alx, augmentation index; Ao-PWV, aortic pulse wave velocity; CCB, calcium channel blocker. augmentation; and the predictive value of treated central BP on cardiovascular mortality and associated outcomes. ${ }^{6,22} \mathrm{In}$ the CAFE study, 2,073 individuals were included in the final analysis and baseline demographic and clinical characteristics were similar in the 2 groups.

The primary antihypertensive (maximum dose $100 \mathrm{mg} /$ day of atenolol or maximum dose $10 \mathrm{mg}$ /day of amlodipine) was administered following a specific stepwise algorithm with bendroflumethiazide (maximum dose $2.5 \mathrm{mg}$ /day in atenolol arm) or perindopril (maximum dose $8 \mathrm{mg} /$ day in amlodipine arm) added as necessary in order to achieve target BPs of $<140 / 90 \mathrm{~mm} \mathrm{Hg}$ for nondiabetics and $<130 / 80 \mathrm{~mm} \mathrm{Hg}$ for patients with diabetes. Antihypertensive drug doses were revised regularly at 6-monthly intervals and arterial stiffness measurements averaging 3.4 follow-up measurements per patient were available at the end of the study. Ninety-five percent of patients were on at least 2 BP-lowering drugs, with $56 \%$ on amlodipine \pm perindopril combination and $60 \%$ on atenolol \pm thiazide combination. ${ }^{6}$

Applanation tonometry for central aortic pressure, AIx and Ao-PWV were performed along with brachial BP recordings. In this study, BP load for each treatment arm was presented as the mean area under the curve (AUC). From baseline, significant reductions in brachial BP were observed in both groups. However, there was an insignificant difference in brachial systolic BPs throughout the CAFE study (AUC difference, $0.7 \mathrm{~mm} \mathrm{Hg}$; 95\% confidence interval [CI], -0.4 to $1.7 ; P=0.2$ ).

In contrast to the brachial BP results, derived central aortic systolic pressures were substantially lower with amlodipine \pm perindopril-based therapy (AUC difference, $4.3 \mathrm{~mm} \mathrm{Hg}$; 95\% CI, 3.3-5.4; $P<0.0001)$ as compared with atenolol \pm bendroflumethiazide. Similar significant differences in central aortic PP and to a smaller extent, central diastolic BP in favor of amlodipine \pm perindopril were also observed. AIx and central APs decrease to a greater extent with amlodipine \pm perindopril. Ao-PWV, however, did not differ between the 2 groups. This suggests that increased wave reflections from distal sites along the arterial tree were primarily responsible for the observed changes in AIx. Important clinical outcomes were evaluated in this study albeit as a secondary outcome. The post hoc defined composite outcomes were cardiovascular events/procedures and development of renal impairment.

Results showed that measures of arterial stiffness such as central aortic PP and brachial PP; central aortic pressure 
wave augmentation; and outgoing pressure wave height were all significantly associated with the composite end point. However, following adjustment for baseline age and other risk factors, only central aortic PP remained significantly associated with the composite clinical outcome. ${ }^{6}$

\section{Combination of an ARB and hydrochlorothiazide vs CCB}

We recently demonstrated in a double-blind, parallel group study, the brachial and central aortic BP-independent effects of an ARB on Ao-PWV. ${ }^{23}$ We studied 144 T2DM patients with systolic hypertension (systolic BP $\geq 140 \mathrm{~mm} \mathrm{Hg}$ and $\mathrm{PP} \geq 60 \mathrm{~mm} \mathrm{Hg}$ ) and microalbuminuria who were randomized to receive the ARB valsartan $(160 \mathrm{mg} /$ day $) \pm$ hydrochlorothiazide (25 mg/day) combination therapy (Val/HCTZ), or dihydropyridine CCB, amlodipine (10 mg/day) for 24 weeks following a 4-week washout with moxonidine (400 mcg/day), a centrally acting antihypertensive agent with limited effects on arterial stiffness. ${ }^{23} \mathrm{HCTZ}$ was added to the ARB to ensure comparable BP-lowering effects. Importantly, the mechanism of action of HCTZ does not involve alteration in vascular tone or arterial wall properties. This approach enabled the BP-independent comparison of 2 widely used antihypertensive classes on Ao-PWV which was the primary end point of the study.

Both brachial and central aortic systolic BP, diastolic BP, and PP fell significantly, and similarly after 24-week treatment in both groups, mean brachial systolic BP $(95 \%$ CI) fell (Val/HCTZ vs amlodipine -23.7 [-28.5, -18.9] vs -19.4 [-24.1, -14.6] mm Hg; brachial diastolic BP -9.4 $[-11.9,-6.9]$ vs $-7.3[-9.8,-4.9] \mathrm{mm} \mathrm{Hg}$; and brachial PP $-14.3[-17.7,-10.8]$ vs $-12.2[-15.5,-8.8] \mathrm{mm} \mathrm{Hg})$. There were no significant differences in the decrease of brachial BP between the 2 groups. Furthermore, there were no between-group differences in mean arterial pressure (MAP) and MAP change. After 24-week treatment, similar significant reductions in central aortic systolic BP (Val/ HCTZ vs amlodipine -23.6 [-28.7, -18.6] vs $-21.1[-26.0$, $-16.3] \mathrm{mm} \mathrm{Hg}$; central diastolic BP -10.4 [-12.9, -7.9] vs $-9.1[-11.5,-6.8] \mathrm{mm} \mathrm{Hg}$; and central aortic PP -13.3 $[-16.9,-9.7]$ vs $-11.9[-15.4,-8.5] \mathrm{mm} \mathrm{Hg}$ ) were observed with no significant between treatment-group differences. Interestingly, after 24 weeks attained mean (standard deviation), brachial and central PP were similar in the 2 groups (61.6 [13.6] and 47.3 [14.1] $\mathrm{mm} \mathrm{Hg}$ in the valsartan/ HCTZ group and 61.5 [12.2] and 47.3 [9.9] $\mathrm{mm} \mathrm{Hg}$ in the amlodipine group). ${ }^{23}$
Mean (95\% CI) Ao-PWV was reduced from baseline by $1.8(-2.4$ to -1.3$) \mathrm{m} / \mathrm{s}$ in Val/HCTZ group $(P<0.0001)$ and by $0.7(-1.3$ to -0.2$)$ in amlodipine group $(P=0.01)$ with an estimated mean $(95 \% \mathrm{CI})$ difference in Ao-PWV change from baseline between the Val/HCTZ and amlodipine group of $-1.1(-1.8$ to -0.5$) \mathrm{m} / \mathrm{s}(P=0.001)$. Significant differences between the 2 groups regarding the ability to reduce Ao-PWV were observed early following 12 weeks of treatment. Albuminuria, a biomarker of cardiorenal risk decrease significantly only in the Val/HCTZ arm. Of note, changes in albumin excretion rate and Ao-PWV were not correlated. Our results suggest that the Val/HCTZ combination improves arterial stiffness as assessed by Ao-PWV to a significantly greater extent than $\mathrm{CCB}$ amlodipine despite similar central and brachial BP control. ${ }^{23}$ This effect may explain the specific BP-independent cardiorenal protective properties of RAAS blockade observed in clinical trials. ${ }^{20,21}$

\section{Combination of an ARB and $C C B$ vs $A R B$ and $H C T Z$}

Matsui et $\mathrm{al}^{24}$ recently studied the effects of add-on treatment with a CCB or diuretic to an ARB on Ao-PWV and central aortic pressures. In this open-label study, 207 patients with essential hypertension received the ARB olmesartan as monotherapy (20 mg OD) for 12 weeks and were then randomized to add-on use of the $\mathrm{CCB}$ azelnidipine ( $\mathrm{n}=103,16 \mathrm{mg}$ OD) or HCTZ ( $\mathrm{n}=104,12.5 \mathrm{mg}$ OD) for 24 weeks. ${ }^{24}$ The authors report that $16 \mathrm{mg}$ OD of azelnidipine is equivalent to a $5 \mathrm{mg}$ OD of amlodipine. After 24 weeks, there was a significantly greater reduction in central aortic systolic BP in the olmesartan/azelnidipine group than that in the olmesartan/HCTZ group with a between-group difference of $5.2 \mathrm{~mm} \mathrm{Hg}$ (95\% CI, 0.3-10.2 mm Hg; $P=0.039)$, despite similar effects on brachial BP. Ao-PWV fell significantly in both groups but was reduced to a greater extent in the olmesartan/azelnidipine group than in the olmesartan/HCTZ group with a between-group difference of $0.8 \mathrm{~m} / \mathrm{s}(95 \%$ CI, $0.5-1.1 \mathrm{~m} / \mathrm{s} ; P<0.001$ ). AIx (adjusted for heart rate) also fell to a greater extent in the olmesartan/azelnidipine group with a significant between-group difference of $2.8 \%$ (95\% CI, 1.3-4.4; $P<0.001)$. Of note, MAP decreased to a significantly greater extent by $4.5 \mathrm{~mm} \mathrm{Hg}(95 \% \mathrm{CI}, 1.5-7.6$; $P<0.004)$ in the olmesartan/azelnidipine group. Following adjustment for this difference in MAP, the effect on Ao-PWV reduction by olmesartan/azelnidipine remained significant but was somewhat diminished with a between-group difference of $0.5 \mathrm{~m} / \mathrm{s}(95 \% \mathrm{CI}, 0.2-0.7 ; P<0.001){ }^{24}$ 


\section{PREterax in regression of Arterial Stiffness in a contrOlled double-bliNd (REASON) study: combination of an ACE-I and diuretic vs $\beta$-blocker}

The REASON trial was a randomized, double-blind study to compare a very low-dose combination of ACE-I, perindopril (2 mg) \pm nonthiazide sulphonamide diuretic, indapamide $(0.625 \mathrm{mg}$; Per/Ind $)$ vs conventional $\beta$-blocker, atenolol $(50 \mathrm{mg})$ in 471 patients with uncomplicated essential hypertension. ${ }^{25}$ Significantly greater reductions in brachial systolic BP and PP were observed in the Per/Ind group than in the atenolol group $(-23.1 \pm 15.6$ vs $-16.2 \pm 16.0 \mathrm{~mm} \mathrm{Hg} ; P<0.001)$ and $(-9.9 \pm 12.4$ vs $-3.3 \pm 13.5 \mathrm{~mm} \mathrm{Hg} ; P<0.001)$, respectively. Brachial diastolic BP was also reduced significantly and similarly in both groups.

A significantly greater decrease in central (carotid and aortic) BPs was observed in the Per/Ind group as compared with atenolol. No significant between-group differences in the Ao-PWV reductions were observed. However, AIx was reduced to a significantly greater extent with Per/Ind. Atenolol lengthens the systolic ejection time while also delaying the peak of the forward pressure wave; hence this may explain the increased augmentation of the pressure wave reflection observed..$^{25}$

\section{ACE-I vs combination therapy with amiloride and HCTZ}

A smaller study of 77 elderly hypertensive patients compared and contrasted the effect of perindopril (2-8 $\mathrm{mg}$ /day) or a diuretic combination of HCTZ (12.5-50 mg/day) \pm amiloride (1.25-5 mg/day) for 9 months, after a 1-month washout with placebo therapy, on carotid artery distensibility and compliance. ${ }^{26}$ Both of these parameters improved significantly in the 2 groups. Of note, the authors suggested that the significant decrease in carotid artery stiffness observed was directly related to the decrease in mean BP observed in both groups. ${ }^{26}$

\section{Other combinations of antihypertensive agents}

Bénétos et $\mathrm{al}^{27}$ compared HCTZ (50 mg) \pm amiloride (5 mg) with captopril $(50 \mathrm{mg}) \pm$ HCTZ $(25 \mathrm{mg}$ ) combination and showed that the ACE-I/diuretic combination decreased arterial wave reflection to a greater extent than the diuretics alone, despite similar BP reductions in both groups.

\section{Comparison of ACE-I vs $\beta$-blocker vs $C C B$ vs thiazide diuretic}

A recently published study of 59 treatment naive patients with isolated systolic hypertension studied the effects of monotherapy with perindopril or atenolol or lercanidipine or bendrofluazide for 10 weeks on arterial stiffness, as measured by radial artery tonometry for estimation of central aortic pressures, AIx, and Ao-PWV. ${ }^{28}$ After a 2-week run-in of placebo therapy, participants were randomized to active monotherapy that was administered in daily doses $(4.0 \mathrm{mg}$ perindopril, $50.0 \mathrm{mg}$ atenolol, $10.0 \mathrm{mg}$ lercanidipine, or $2.5 \mathrm{mg}$ bendrofluazide). Peripheral brachial PP and systolic BP were reduced similarly and significantly in all groups. Atenolol failed to reduce central PP, whereas the other antihypertensive classes significantly reduced all the central hemodynamic parameters. AIx was increased with atenolol, an observation also demonstrated in other larger studies with this agent. ${ }^{25}$ Ao-PWV, however, remained unchanged in all 4 treatment arms. These results suggest that 10 weeks of treatment with submaximal doses of antihypertensive therapy may be insufficient to demonstrate significant changes in Ao-PWV. Alternatively, this cohort of patients may have blunted responsiveness to antihypertensives vis-à-vis reduction in Ao-PWV. ${ }^{28}$

A smaller study in 21 treatment naive hypertensive patients compared the effects of an ARB eprosartan with atenolol. There was a greater reduction in central systolic BP and Ao-PWV $(0.8 \pm 0.1$ vs $0.5 \pm 0.1 \mathrm{~m} / \mathrm{s} ; P<0.005)$, in the atenolol arm compared with eprosartan arm, after 6 weeks of treatment despite similar effects on brachial BP. Of interest, an increase in AIx was observed with atenolol as compared to a reduction in the ARB treatment arm..$^{29}$

\section{Aldosterone antagonist vs CCB}

Animal studies have demonstrated that aldosterone antagonist, spironolactone prevents the accumulation of aortic collagen and reduces aortic stiffness. ${ }^{30}$ Interestingly, in hypertensive subjects, there is positive correlation between increase in plasma aldosterone and arterial stiffness, an effect which also appears independent of $\mathrm{BP}^{31}$ White et a $\mathrm{l}^{32}$ compared effects of the aldosterone antagonist eplerenone with CCB amlodipine, for 24 weeks on arterial stiffness in a cohort 269 patients with systolic hypertension. Patients were randomly assigned to either eplerenone (50-200 mg/day) or amlodipine $(2.5-10 \mathrm{mg} /$ day). ${ }^{32}$ After 24 weeks of therapy, reductions in brachial systolic BP was similar in both treatment arms (eplerenone, $-20.5 \pm 1.1 \mathrm{~mm} \mathrm{Hg}$; amlodipine, $-20.1 \pm 1.1 \mathrm{~mm} \mathrm{Hg}$ ). PP also decreases similarly from baseline in both groups (eplerenone, $-15.9 \mathrm{~mm} \mathrm{Hg}$; amlodipine, $-13.4 \mathrm{~mm} \mathrm{Hg}$ ). At the end of the 
study, Ao-PWV had decreased significantly from baseline in the eplerenone and amlodipine groups by 2.1 and $2.4 \mathrm{~m} / \mathrm{s}$, respectively; however, there was no significant difference between the 2 treatment groups. ${ }^{32}$

\section{Combination therapy with ACE-I and $A R B$ vs monotherapy}

The combination of valsartan and captopril on Ao-PWV and AIx was studied in 12 patients with essential hypertension. In this short, 4-week randomized crossover study, valsartan (160 mg/day) vs captopril (100 mg/day) was compared, followed by comparison between combination therapy and monotherapy. Combination therapy reduced Ao-PWV and AIx more when compared with monotherapy, even when differences in BP were corrected for. The effects of valsartan vs captopril on Ao-PWV and AIx were similar. ${ }^{33}$ However, in light of recent concerns on the safety of combination therapy with an ACE-I and ARB on renal end points and lack of demonstrable cardiovascular benefits, it is unclear whether such an approach should be continued in clinical practice. $^{34}$

\section{$\beta$-blockers, $\alpha$-blockers, and nitrates}

Some authors have suggested that $\beta$-blockers, with vasodilating properties, such as nebivolol may have a beneficial effect on wave reflection. A recent study compared atenolol with nebivolol in 40 untreated patients with hypertension. Both drugs reduced Ao-PWV to a similar extent. However, only nebivolol demonstrated a reduction in AIx. ${ }^{35}$ Another study in 16 treatment naive patients with isolated systolic hypertension showed similar results. Nebivolol and atenolol reduced brachial BP and Ao-PWV to a similar degree. Interestingly, in this study, nebivolol reduced central aortic PP more than atenolol with a less pronounced rise in AIx. ${ }^{36}$

There is conflicting evidence on the effects of $\alpha$-receptor blocking agents such as doxazosin on arterial stiffness. One nonrandomized study reported improvements in Ao-PWV and AIx. ${ }^{37}$ However, another study demonstrated reduction in AIx only. ${ }^{38}$

Nitrates have a pronounced acute effect on the arterial pressure waveform but have limited effect on aortic stiffness. ${ }^{2,39}$ At present, however, there are no long-term studies evaluating the effects of nitrates on markers of arterial stiffness with most studies being of short duration.

\section{Endothelin and arterial stiffness}

Vuurmans et $\mathrm{al}^{40}$ demonstrated that infusion of endothelin-1, at concentrations found in renal disease, into healthy volunteers reduced brachial MAP, Ao-PWV, and AIx. The concomitant use of an endothelin-1 receptor blocker prevented these effects. ${ }^{40}$

In patients with nondiabetic chronic kidney disease and proteinuria, acute use of a selective endothelin-A receptor antagonist reduced BP, proteinuria, and arterial stiffness when added to standard treatment. ${ }^{41}$ The effects on arterial stiffness appeared at least, in part independent of BP. However, long-term studies are required to confirm these preliminary findings. Further concerns have been raised recently on the use of endothelin-A receptor antagonists in routine clinical practice as they can increase the risk of fluid retention and congestive heart failure in T2DM patients with nephropathy. ${ }^{42}$

\section{Conclusion}

There is emerging evidence that modulation of arterial stiffness independent of BP reduction is now possible. Importantly, data from patients with end stage renal disease indicate that reversibility in Ao-PWV in response to ACE-I treatment is associated with reduced mortality independent of brachial BP. Our data and that of other authors suggest that drugs that interfere with RAAS reduce arterial stiffness, an effect that may be independent of their BP-lowering effects. The results from the CAFE study suggest that greater cardiovascular protection is observed with drugs that differentially lower central aortic pressures rather than only brachial BP. Many hypertensive patients will require combination therapy to ensure optimal BP control. The current evidence indicates that RAAS blockade with an ACE-I or ARB in combination with a thiazide diuretic and or CCB are therapies that are most likely to ameliorate arterial ageing and reduce arterial stiffness. However, further long-term studies are required to conclusively prove that reduction in Ao-PWV or other parameters of arterial stiffness per se directly translates to reduction in cardiovascular events.

\section{Summary of terms}

Arterial elasticity: elastic modulus is defined as the pressure change needed for a theoretical 100\% stretch from diameter at rest.

Arterial distensibility: the inverse of the elastic modulus ie, the relative change in diameter (or area) for a given pressure change.

Arterial compliance: absolute diameter (or area) change for any given pressure. This is a measure of the capacity of the arterial system to accommodate further increase in volume. 


\section{Disclosures}

The authors report no conflicts of interest in this work.

\section{References}

1. Nicols WW, O'Rourke MF. McDonald's Blood Flow in Arteries: Theoretical Experimental and Clinical Principles. Edward Arnold: London. 1998:54-113.

2. Laurent S, Cockcroft J, Bortel L, Boutouyrie P, Giannattasio C, Daniel Hayoz D, et al. European network for non-invasive investigation of large arteries expert consensus document on arterial stiffness: methodological issues and clinical applications. Eur Heart J. 2006;27: 2588-2605.

3. Protogerou AD, Papaioannou TG, Lekakis JP, Blacher J, Safar ME. The effect of antihypertensive drugs on central blood pressure beyond peripheral blood pressure. Part I: (patho)-physiology, rationale and perspective on pulse pressure amplification. Curr Pharm Des. 2009;15: 267-271.

4. Greenwald SE. Ageing of the conduit arteries. J Pathol. 2007;211: $157-172$.

5. Safar ME, Levy BI, Struijker-Boudier H. Current perspectives on arterial stiffness and pulse pressure in hypertension and cardiovascular diseases. Circulation. 2003;107:2864-2869.

6. Williams B, Lacy PS, Thom SM, Cruickshank K, Stanton A, Collier D, et al; for CAFE Investigators; Anglo-Scandinavian Cardiac Outcomes Trial Investigators; CAFE Steering Committee and Writing Committee. Differential impact of blood pressure-lowering drugs on central aortic pressure and clinical outcomes: principal results of the Conduit Artery Function Evaluation (CAFE) study. Circulation. 2006;113:1213-1225.

7. Laurent $S$, Boutouyrie P. Recent advances in arterial stiffness and wave reflection in human hypertension. Hypertension. 2007;49:1202-1206.

8. Kelly RP, Millasseau SC, Ritter JM, Chowienczyk PJ. Vasoactive drugs influence aortic augmentation index independently of pulse-wave velocity in healthy men. Hypertension. 2001;37:1429-1433.

9. O'Rourke MF, Mancia G. Arterial stiffness. J Hypertens. 1999;17: $1-4$.

10. O'Rourke MF, Nichols WW, Safar ME. Brachial and central arterial pressure. Hypertension. 2006;48:e1.

11. McEniery CM, Yasmin, Hall IR, Qasem A, Wilkinson IB, Cockcroft JR. Normal vascular aging: differential effects on wave reflection and aortic pulse wave velocity: the Anglo Cardiff Collaborative Trial (ACCT). J Am Coll Cardiol. 2005;46:1753-1760.

12. Laurent S, Katsahian S, Fassot C, et al. Aortic stiffness is an independent predictor of fatal stroke in essential hypertension. Stroke. 2003;34:1203-1206.

13. Blacher J, Safar ME, Guerin AP, Pannier B, Marchais SJ, London GM. Aortic pulse wave velocity index and mortality in end-stage renal disease. Kidney Int. 2003;63:1852-1860.

14. Guerin AP, Blacher J, Pannier B, Marchais SJ, Safar ME, London GM. Impact of aortic stiffness attenuation on survival of patients in end-stage renal failure. Circulation. 2001;103:987-992.

15. London GM. Brachial arterial pressure to assess cardiovascular structural damage: an overview and lessons from clinical trials. J Nephrol. 2008;21:23-31.

16. Stehouwer CD, Henry RM, Ferreira I. Arterial stiffness in diabetes and the metabolic syndrome: a pathway to cardiovascular disease. Diabetologia. 2008;51:527-539.

17. Blacher J, Asmar R, Djane S, London GM, Safar ME. Aortic pulse wave velocity as a marker of cardiovascular risk in hypertensive patients. Hypertension. 1999;33:1111-1117.

18. Zieman SJ, Melenovsky V, Kass DA. Mechanisms, pathophysiology, and therapy of arterial stiffness. Arterioscler Thromb Vasc Biol. 2005;25:932-943.
19. Luft FC. Angiotensin, inflammation, hypertension, and cardiovascular disease. Curr Hypertens Rep. 2001;3:61-67.

20. Guidelines Committee. 2003 European Society of Hypertension European Society of Cardiology guidelines for the management of arterial hypertension. J Hypertens. 2003;21:1011-1053.

21. Williams B, Poulter NR, Brown MJ, et al; for British Hypertension Society. Guidelines for management of hypertension: report of the fourth Working Party of the British Hypertension Society, 2004-BHS IV. J Hum Hypertens. 2004;18:139-185.

22. Williams B, O’Rourke M; for Anglo-Scandinavian Cardiac Outcomes Trial. The Conduit Artery Functional Endpoint (CAFE) study in ASCOT. J Hum Hypertens. 2001;15 Suppl 1:S69-S73.

23. Karalliedde J, Smith A, DeAngelis L, et al. Valsartan improves arterial stiffness in type 2 diabetes independently of blood pressure lowering. Hypertension. 2008;51:1617-1623.

24. Matsui Y, Eguchi K, O’Rourke MF, et al. Differential effects between a calcium channel blocker and a diuretic when used in combination with angiotensin II receptor blocker on central aortic pressure in hypertensive patients. Hypertension. 2009;54:716-723.

25. Asmar RG, London GM, O'Rourke ME, Safar ME; for REASON Project Coordinators and Investigators. Improvement in blood pressure, arterial stiffness and wave reflections with a very-low-dose perindopril/ indapamide combination in hypertensive patient: a comparison with atenolol. Hypertension. 2001;38:922-926.

26. Girerd X, Giannattasio C, Moulin C, Safar M, Mancia G, Laurent S. Regression of radial artery wall hypertrophy and improvement of carotid artery compliance after long-term antihypertensive treatment in elderly patients. J Am Coll Cardiol. 1998;31:1064-1073.

27. Bénétos A, Laflèche A, Asmar R, Gautier S, Safar A, Safar ME. Arterial stiffness, hydrochlorothiazide and converting enzyme inhibition in essential hypertension. J Hum Hypertens. 1996;10:77-82.

28. Mackenzie IS, McEniery CM, Dhakam Z, Brown MJ, Cockcroft JR, Wilkinson IB. Comparison of the effects of antihypertensive agents on central blood pressure and arterial stiffness in isolated systolic hypertension. Hypertension. 2009;54:409-413.

29. Dhakam Z, McEniery CM, Yasmin, Cockcroft JR, Brown MJ, Wilkinson IB.Atenolol and eprosartan: differential effects on central blood pressure and aortic pulse wave velocity. Am J Hypertens. 2006;19:214-219.

30. Benetos A, Lacolley P, Safar ME. Prevention of aortic fibrosis by spironolactone in spontaneously hypertensive rats. Arterioscler Thromb Vasc Biol. 1997; 17:1152-1156.

31. Blacher J, Amah G, Girerd X, et al. Association between increased plasma levels of aldosterone and decreased systemic arterial compliance in subjects with essential hypertension. Am J Hypertens. 1997; 10:1326-1334.

32. White WB, Duprez D, St Hillaire R, et al. Effects of the selective aldosterone blocker eplerenone versus the calcium antagonist amlodipine in systolic hypertension. Hypertension. 2003;41:1021-1026.

33. Mahmud A, Feely J. Reduction in arterial stiffness with angiotensin II antagonist is comparable with and additive to ACE inhibition. Am J Hypertens. 2002;15:321-325.

34. Messerli FH. The sudden demise of dual renin-angiotensin system blockade or the soft science of the surrogate end point. $J$ Am Coll Cardiol. 2009;53:468-470.

35. Mahmud A, Feely J. Beta-blockers reduce aortic stiffness in hypertension but nebivolol, not atenolol, reduces wave reflection. Am J Hypertens. 2008;21:663-667.

36. Dhakam Z, Yasmin, McEniery CM, Burton T, Brown MJ, Wilkinson IB. A comparison of atenolol and nebivolol in isolated systolic hypertension. J Hypertens. 2008;26:351-356.

37. Komai N, Ohishi M, Moriguchi A, YanagitaniY, Jinno T, Matsumoto K, etal. Low-dose doxazosin improved aortic stiffness and endothelial dysfunction as measured by noninvasive evaluation. Hypertens Res. $2002 ; 25: 5-10$. 
38. Mahmud A, Feely J, Doxazosin reduces augmentation index but not pulse wave velocity in essential hypertension. Br J Clin Pharmacol. 2006;61:628.

39. Fitchett DH, Simkus GJ, Beaudry JP, Marpole DG. Reflected pressure waves in the ascending aorta: effect of glyceryl trinitrate. Cardiovasc Res. 1988;22:494-500.

40. Vuurmans TJ, Boer P, Koomans HA. Effects of endothelin-1 and endothelin-1 receptor blockade on cardiac output, aortic pressure, and pulse wave velocity in humans. Hypertension. 2003;41:1253-1258.
41. Dhaun N, Macintyre IM, Melville V, et al. Effects of endothelin receptor antagonism relate to the degree of renin-angiotensin system blockade in chronic proteinuric kidney disease. Hypertension. 2009;54: 113-119.

42. Mann JF, Green D, Jamerson K, et al; for the ASCEND Study Group. Avosentan for overt diabetic nephropathy. J Am Soc Nephrol. 2010;21:527-535

Integrated Blood Pressure Control

\section{Publish your work in this journal}

Integrated Blood Pressure Control is an international, peer-reviewed open-access journal focusing on the integrated approach to managing hypertension and risk reduction. Treating the patient and comorbidities together with diet and lifestyle modification and optimizing healthcare resources through a multidisciplinary team approach constitute key features of the journal. This journal is indexed on American Chemical Society's Chemical Abstracts Service (CAS). The manuscript management system is completely online and includes a very quick and fair peerreview system, which is all easy to use. Visit http://www.dovepress.com/ testimonials.php to read real quotes from published authors.

\footnotetext{
Submit your manuscript here: http://www.dovepress.com/integrated-blood-pressure-control-journal
} 